\title{
Humanizar-se como processo educativo em missões populares de uma entidade filantrópica
}

\author{
Humanization as an educative process in popular missions of a \\ philanthropic entity
}

Bruno Martins Ferreira ${ }^{1}$

Luana Zanotto ${ }^{2}$

Fernando Donizete Alves ${ }^{3}$

\section{Resumo}

Este artigo busca compreender os processos educativos consolidados com pessoas assistidas por uma entidade filantrópica em missões populares na área da saúde e refletir questões da humanização e da alteridade no trato das relações humanas. Reconhecemos a existência de processos educativos em práticas sociais desta origem, circunstâncias em que o ser humano se refaz como pessoa e estabelece particularidades no grupo no qual se insere. Com isso, pautado no viés da pesquisa social, o estudo contou com a participação de onze sujeitos, entre eles os membros da entidade e as pessoas assistidas. A partir das visitações junto à entidade, foi construído um conjunto de diários de campo. As experiências registradas foram analisadas na perspectiva qualitativa. A organização dos dados se deu com base na análise de conteúdo. Os resultados revelaram as seguintes categorias: i) aprendizados nas trocas de saberes de 'experiência feito', it) educar-se com o diálogo: a prática amorosa na alteridade. Na primeira, emergiram aprendizagens significativas nas trocas de saberes de experiências entre as pessoas, sobretudo acerca dos saberes populares em saúde. A segunda, por sua vez, demonstrou ser possivel educar-se na dialogicidade, a partir da prática amorosa sedimentada na alteridade. Assim, as visitações possibilitaram o compartilhamento e compreensões de mundos distintos, tendo no respeito e na amorosidade as condições

\footnotetext{
${ }^{1}$ Mestrando em Educação pelo programa de pós-graduação em Educação Universidade Federal de São Carlos e Licenciado em Educação Física pela mesma Instituição.E-mail: brunomartinsufscar@hotmail.com

${ }^{2}$ Doutoranda e mestre em Educação, licenciada em Educação Física. Docente substituta do Departamento de Metodologia de Ensino (DME) da Universidade Federal de São Carlos.E-mail: luanazanotto@yahoo.com.br

${ }^{3}$ Doutor em Educação Escolar, licenciado em Educação Física. Professor no Programa de Programa de Pós-Graduação em Educação e do Departamento de Educação Física e Motricidade Humana da Universidade Federal de São Carlos.E-mail: alves.sommer@gmail.com
} 
primordiais para a valorização das visões de mundo dos envolvidos no processo.

Palavras-chave: Processo Educativo. Prática Social. Humanização. Alteridade.

\begin{abstract}
This article aims to comprehend the educative processes that were consolidated with people assisted by a philanthropic entity in popular missions of the health area. Additionally, there is a critical reflection of issues related to humanization and otherness in human relationships. It is recognized the existence of educative processes in social practices of this genesis, in which, due to the circumstances, the human being rebuilds itself and establishes particularities in the group in which is inserted.Therefore, founded on social research bias, this study had the participation of eleven subjects, including the members of the entity and the assisted people. The information obtained from data collection of the entity was used to construct a range of field diaries. The registered experienceswere analysed, based on a qualitative perspective. Data organization was built through content analysis. Results revealed the following categories: i) Learning from the exchange of knowledge in 'experiênciafeito' ii) Educating through dialogue: the amorous practice in otherness. Firstly, significative learnings emerged from the exchange of knowledge and experiences among people, mainly related to the popular knowledge about health. Secondly, it demonstrated to be possible to educate through dialogism from the amorous practice based on otherness. Thus, the visitations made possible the sharing and comprehension of distinct worlds, in which respect and love were pivotal to the valorization of the points of view of the ones involved in the process.
\end{abstract}

Keywords: Educative Processes. Social Practices. Humanization.

Otherness.

\title{
1. INTRODUÇÃO
}

O presente artigo foi elaborado a partir das experiências vivenciadas com pessoas assistidas por uma entidade filantrópica em missões populares na área da saúde, pautada na caridade para a realização de sua missão popular. As vivências, revertidas em uma dinâmica de inserção foram desenvolvidas na perspectiva da prática social (OLIVEIRA et al., 2009). A escolha por pesquisar 
as particularidades deste grupo partiu de motivações de cunho histórico e de busca por ações humanizadoras que permitem conhecer novas realidades e empenhar o exercício da alteridade, confrontando assim as percepções subjetivas de mundo em respeito aos outros mundos que somente se desvelam do processo de educação, conhecimento e convivência.

Para além desses anseios, a temática investigada neste artigo abarca o objeto de estudo eleito para a construção de um relatório final solicitado como requisito avaliativo de uma disciplina do curso de Pós-Graduação em Educação de uma Universidade Federal do interior paulista, intitulada "Estudos em Práticas Sociais e Processos Educativos I".

A referida disciplina busca compreender práticas sociais em diferentes contextos educacionais. Seus preceitos teóricos estão sumariamente sedimentados na perspectiva de estudiosos latinoamericanos, tais como, Paulo Freire, Ernani Maria Fiori e Enrique Dussel e, com eles, identificam-se práticas sociais em diferentes contextos e comunidades, assim como se compreende os processos educativos decorrentes dessas práticas - do educar e se educar - constituindo os/as pesquisadores(as) e participantes de pesquisas em verdadeiras comunidades de trabalho.

Com a intenção de compreender as construções que partem das relações humanas desenvolvidas em missões populares de uma entidade filantrópica, o presente estudo foi orientado pela seguinte questão: que processos educativos de humanização se desvelam da prática social das missões populares de saúde numa entidade filantrópica? Nessa direção, objetivamos compreender os processos educativos consolidados em missões populares de 
saúde, além de acender reflexões acerca da humanização e da alteridade no trato das relações humanas.

\section{REFERENCIAL TEÓRICO}

Preliminarmente neste estudo, as significações adotadas para o termo prática social encontram-se relacionadas ao conceito de cultura, no qual o ser humano faz e se refaz como ser humano/pessoa, constrói seus valores e tem a possibilidade de determinar a forma particular de vida do grupo no qual se insere (SILVA, 2004). Práticas sociais são concebidas pelas ações decorrentes do convivio entre pessoas, consideradas atores participantes das relações concretizadas em diferentes contextos, ambientes, propósitos e significados. Dessa forma, criam-se as distintas identidades, ou seja, "[...] se concretizam em relações que estruturam as organizações das sociedades" (OLIVEIRA et al., 2009, p. 5).

Em diálogo, Cota (2000, p. 200) afirma:

[...] os conhecimentos são construídos em práticas sociais, das quais participamos, quando se integram às críticas que deles fazemos, orientam nossas ações, formando-nos. Esta formação decorre de uma práxis que vamos construindo em colaboração com aqueles com quem vivemos. As práticas sociais se produzem no intercâmbio que as pessoas estabelecem entre si ao significar o mundo que as cerca e ao intervir nele.

Olhamos para as práticas sociais de cunho educativo como um caminho possivel para a modificação e transformação da realidade humana, consolidadas em um contexto no qual as pessoas ensinam, ao passo em que também aprendem. $O$ educador Paulo Freire, em sua obra Pedagogia da Esperança (1992), traz que ser consciente prescinde à condição do ser 
humano o reconhecimento de que se encontra num processo constante de devir, de vir a ser. Assim, consciente de sua inconclusão (FREIRE, 1987), o ser humano não pode ser considerado como uma realidade fadada, acabada, mas sim como um ser na intermitente busca pela transcendência, superação, o que é identificado como um processo de humanização.

Ao pensar essas possibilidades em práticas sociais, temos que essas são promotoras da formação para a vida na sociedade, por meio dos processos educativos que se desencadeiam (OLIVEIRA et al., 2009, p. 4). Nas palavras dos autores e autoras supracitados, "os processos educativos decorrem de e geram interações entre os indivíduos e entre eles e os ambientes, natural, social, cultural em que vivem". Nesse entorno faz-se oportuno elucidar outros conceitos acercada expressão 'processos educativos', isto é, como ações envolvidas na busca permanente do homem por autonomia e liberdade. Para Fiori (1986, p. 84), isso é entendido como:

[...] um esforço permanente do homem por constituir-se e reconstituir-se, buscando a forma histórica na qual possa reencontrar consigo mesmo, em plenitude de vida humana, que é, substancialmente, comunhão social. Esse reencontro coloca o homem em seu lugar próprio, tem um nome adequado: autonomia e liberdade. $O$ movimento em direção à liberdade define o sentido do processo educativo como libertação. A educação, pois, é libertadora ou não é educação.

A busca se dá pela participação ativa do próprio homem, protagonista da sua história do mundo e libertação e isso se apresenta como dinâmica de conscientização e diálogo, em que os seres humanos poderão tornar-se sujeitos no processo educativo, bem como na construção de sua humanidade. Nesse panorama, 
os processos educativos se apresentam como ações genuinamente humanas, constituídos nas trocas de saberes entre e com os sujeitos, edificando também as concepções do próprio homem e do mundo, na medida que a convivência entre os diferentes mundos possibilitem permutas de aprendizagens.

Assim, pesquisar processos educativos em práticas sociais é também identificar e compreender as relações do educar e do se educar entre pesquisadores e participantes de pesquisas. Com isso, o conceito de educação empregado no presente artigo extrapola a concepção institucionalizada culturalmente calcada na escolarização. Ao invés disso, acreditamos que as pessoas se educam em comunhão nos mais diversos espaços. Nesse ínterim, abordar as distintas realidades sociais a partir das perspectivas dos desqualificados e marginalizados pela sociedade é mais do que somente um interesse científico, passa a ser compromisso e responsabilidade social.

Refletindo sobre a importância e relevância da convivência no processo contínuo de humanização como projeto da humanidade, não se pode abrir mão desse conceito-chave para aprender em comunhão a perspectiva do outro, na sua alteridade e, assim, compartilhar as existências sociais e saberes captados pela consciência crítica aplicada na própria realidade. Segundo Oliveira e Stotz (2004, p. 15), conviver se traduz pela

arte de se relacionar, dá intensidade à relação, sabor ao fazer e gera afetividade e saber [...]. Conviver se aprende convivendo e para essa convivência há algumas moedas: simpatia, confiança, humildade, sensibilidade, respeito, flexibilidade em relação aos tempos.

Nesse prisma, a ideia de conviver se fortalece como permissiva à existência do outro, transpassando também a ideia de que a produção de um dado conhecimento, seja empírico ou 
científico, não se limita ao trabalho de campo, mas sim à construção do conviver, nas aproximações das intersubjetividades. Com isso, Freire (1992) nos convida a observar o mundo com um olhar mais humanizador, sustentado pela conscientização e dialogicidade, de modo a mediar as transformações cabíveis em nossos mundos pela consciência que se tem de reconhecer e problematizar a própria inconclusão humana e também a do outro.

Na ótica freireana, o diálogo é entendido como o momento de encontro humano para reflexões sobre suas realidades e implica saberes diferentes, os quais não podem ser impostos por alguém, mas sim emergem a partir da comunicação crítica e esperançosa sobre as distintas condições no mundo. Tal prática exige confiança no outro, disponibilidade, amor, respeito e humildade (FREIRE, 1982). O diálogo propriamente consolidado na relação inter-humana se constitui no ponto de partida enquanto resposta à alteridade.

Não podemos negar que essas relações são sustentadas em saberes vivenciados e apreendidos com os episódios da vida cotidiana. Sobre isso, Freire (1982) faz alusão à expressão "saber de experiência feito" que se refere às experiências de vida trazidas pelos sujeitos e que devem ser consideradas em seus contextos históricos, politicos, econômicos e sociais. Tais experiências são tomadas como ponto de partida nas relações humanas e traduzem a leitura de mundo das pessoas. Esse conceito é tido como compreensão sobre o saber imediato que caracteriza a cotidianidade do sujeito, ou seja, como reconhecimento da bagagem que cada ser humano carrega consigo. O termo ainda representa uma importante contribuição à valorização do senso 
comum, para que se perceba que "[...] não há saber nem ignorância absoluta, há somente uma relativização do saber ou da ignorância" (FREIRE, 1982, p. 29).

Mediante os conceitos destacados, bem como os saberes e conhecimentos que perpassam a humanização, o diálogo, a alteridade e a conscientização imbricados nos processos educativos desencadeados em práticas sociais, movidos pelo entendimento de que ninguém educa ninguém, como tampouco ninguém se educa a si mesmo: os homens [e as mulheres] se educam em comunhão (FREIRE, 1992). Coerentemente, devemos olhar para as pessoas, sobretudo para grupos marginalizados pela sociedade, a fim de desvelar conhecimentos, atitudes e as relações dos grupos sociais para uma possivel compreensão de práticas e processos educativos autorais.

Por esse viés, de postura frente ao mundo e empreendida nesta pesquisa, busca-se identificar e analisar ações junto a uma entidade filantrópica que tem como missão a promoção da saúde e dignidade humana, consolidadas em visitações sistematizadas em casas de famílias social e economicamente menos favorecidas, residentes de bairros periféricos de uma cidade do interior paulista.

\section{METODOLOGIA}

Tendo em vista cotejar os objetivos de investigação, tomamos como pressuposto metodológico a realização de uma pesquisa com enfoque qualitativo (BOGDAN; BIKLEN, 1994), paradigma científico pelo qual se interpreta a realidade e o contexto social do indivíduo. Esse enfoque de pesquisa atribui um caráter minucioso de apreensão dos gestos, expressões, comportamentos e atitudes, 
assim como apresenta os detalhes e entendimentos necessários para compreensão da realidade.

Somado a isso, elegemos uma abordagem exploratória e de cunho social, pesquisando/convivendo com pessoas assistidas pela entidade filantrópica em sua missão popular, pois a pesquisa social compreende o processo de investigação como produção conjunta aos sujeitos presentes no espaço destinado à coleta de dados. Sobre isso, Minayo (2001, p. 54) caracteriza o campo de coleta enquanto:

[...] ocupado pelas pessoas e grupos convivendo numa dinâmica de interação social. Essas pessoas e esses grupos são sujeitos de uma determinada história a ser investigada [...] o campo torna-se um palco de manifestações de intersubjetividades e interações entre pesquisador e grupos estudados, propiciando a criação de novos conhecimentos (grifo dos autores).

Em vias de realização da pesquisa, foi concedida aos pesquisadores a autorização pela coordenação do grupo, devidamente registrado em termos éticos elaborados para o estudo. Assim, ao tratar dos preceitos éticos no que se refere à participação de pessoas em pesquisas, fora apresentado o termo de Consentimento Livre e Esclarecido (TCLE) para fins de coleta de assinaturas de todos e todas participantes de pesquisa, tanto dos e das integrantes da entidade filantrópica como dos sujeitos visitados durante o processo, respeitando assim as premissas de anonimato (utilização de nomes fictícios) e a confidencialidade dos dados.

Recorrendo brevemente à origem da entidade pesquisada, temos que a mesma é oriunda da França, sendo em 1833 o ano de sua fundação. De caráter global, tal instituição chegou ao Brasil 
em 1872 e, desde então, visa cumprir o objetivo de assistir e atender com caridade a todas pessoas em estado de vulnerabilidade social (SSVP BRASIL, 2017).

Tendo como missão aliviar a miséria espiritual e material dos que vivem em situação de risco social, colocando em prática os ensinamentos do Cristianismo, atualmente tal entidade se encontra presente em 150 países, com mais de 800 mil membros, sendo 153 mil brasileiros, o que configura nosso país como o que mais voluntários possui, atendendo mais de meio milhão de pessoas dentro do território nacional. A administração da entidade em território brasileiro é de responsabilidade de um Conselho Nacional submisso ao Conselho Geral Internacional, com sede em Paris, na França.

O grupo de voluntários acompanhado neste estudo é constituído por homens e mulheres, idosos e idosas, adultos, adolescentes e crianças que se reúnem semanalmente para discutir, debater e sugerir maneiras para atender um seleto grupo de famílias carentes residentes de bairros adjacentes às igrejas católicas vinculadas à entidade filantrópica. O grupo conta com dez membros frequentes, sendo que em todas as visitações estavam presentes pelo menos a coordenadora geral e mais um membro do grupo.

As ajudas, auxilios e assistências oferecidos pelos voluntários contemplam a organização de cursos de alfabetização e indicações de trabalhos para colaboração à renda familiar, distribuição de gêneros alimentícios, remédios, roupas, utensílios para reformas de residências, materiais escolares e similares.

Para consolidar a assistência, primeiramente é feito um mapeamento prévio de famílias ou pessoas em situações de 
vulnerabilidade social e, posteriormente, realiza-se um preenchimento de cadastro socioeconômico para que se possa precisar e entender as necessidades de cada núcleo familiar ou de cada sujeito, desde que esses aceitem os auxílios ofertados pela entidade. Para além de tais apontamentos, a visitação é considerada como a principal atividade dos voluntários, pois nessa ação pretende-se materializar o lema da entidade (SVVP BRASIL, 2017), traduzido pela missão: "formar uma grande rede de caridade de ajuda ao próximo", na busca pelo incentivo à promoção da dignidade humana.

As visitações propriamente consistiram em idas regulares, num período médio de 21 dias, aos locais de moradia dos assistidos, em vistas da promoção humana. Nessas instâncias ocorrem diálogos para a compreensão das angústias e necessidades apontadas pelos assistidos, de modo coerente com os princípios que tangem a caridade, ou seja, auxiliando na melhor maneira a condução da vida dessas pessoas, com gestos e bens materiais, com palavras de alento, incentivo e esperança (tendo por base os ensinamentos do cristianismo), ações que buscam resgatar uma vida de qualidade e a qualidade de vida (BRANDÃO, 2005).

Procurando exercitar a ideia do conhecer (LAROSSA, 2002) e considerando as necessidades de se conscientizar (FIORI, 1986), a intenção de conviver junto aos integrantes da entidade filantrópica e as pessoas por eles assistidas precedeu a suspensão de valores, concepções e julgamentos. Esse exercício de alteridade e humildade, como dito por Freire (1992), almeja um melhor sentir, melhor perceber, melhor olhar, melhor escutar e melhor ser, junto àqueles e àquelas que fazem acontecer as visitações. 
Destacamos que a investigação ora debatida ocorreu junto às ações de visitações a núcleos familiares em suas residências, situadas em bairros periféricos de uma cidade do interior do Estado de São Paulo, Brasil. Tais inserções como modo de visitação aconteceram semanalmente ao longo dos meses de abril a junho do ano de 2016, com duração média de uma hora cada encontro. Foram sujeitos desse estudo um total de onze participantes, entre eles os membros da entidade e as pessoas assistidas. Em cada uma das missões de visitação havia pelo menos três pessoas, além da presença do pesquisador.

Como ferramenta à coleta dos dados, um conjunto de nove inserções/missões foi registrado em diários de campo. Segundo Bogdan e Biklen (1994), o diário de campo é um instrumento proficuo para relatar os escritos daquilo que o investigador ouve, vê, experiencia e pensa no decurso da recolha, refletindo sobre os dados de um estudo qualitativo. A participação do pesquisador nessas missões se deu de modo contínuo e em decorrência da autorização/convite da coordenação do grupo para acompanhá-los em determinadas ocasiões.

Dos nove diários de campo, apenas seis foram eleitos para a composição desse artigo, por evidenciarem aspectos referentes à capacidade do pesquisador em 'se colocar no lugar' das pessoas participantes das missões, de modo a sentir e/ou expressar o que elas estavam sentindo. A aparição desses aspectos, ou seja, o potencial de perceber o outro a partir da própria realidade, potencializou as chances de criar discussões favoráveis para alcançar e fazer entender os objetivos propostos no estudo, sobretudo a nossa convicção de que fazemos pesquisas com as pessoas e não sobre elas. 
Após as densas leituras e releitura dos diários de campo, com média de seis páginas cada um, organizamos categorias temáticas em consonância com os objetivos propostos, que, segundo Bardin (1979), permitem inferir saberes relativos às condições de produção das mensagens.

Esse processo demandou a criação de um modo próprio e didático para visualização das informações, visando ofertar um código para os trechos lidos e interpretados. Sendo assim, cada trecho correspondente a uma determinada interpretação foi sublinhado para que as possiveis categorias se tornassem mais compreensiveis.

Salientamos que a categorização dos dados foi sustentada pelo agrupamento de ideias, elementos e expressões, o que ocasionou nesse estudo a formação de duas categorias, respectivamente nomeadas: i) aprendizados nas trocas de saberes de 'experiência feito', ii) educar-se com o diálogo: a prática amorosa na alteridade. Ambas as categorias foram construídas no exercício perceptivo de similitudes dos conteúdos descritos nos diários de campo, bem como no convívio com os sujeitos.

Diante da riqueza de aprendizagens durante as inserções, faz-se necessário sinalizar alguns limites perpassados pela análise que segue, sobretudo porque mantivemos o foco da investigação nas relações humanas, bem como nas trocas de saberes de experiência feito (FREIRE, 1982) e no educar-se na dialogicidade. 


\section{APRESENTAÇÃO E DISCUSSÃO DOS RESULTADOS}

\subsection{Aprendizados nas trocas de saberes de 'experiência feito'}

Ao visitar os distintos lares junto aos integrantes da entidade filantrópica podemos identificar os mais diversos saberes e fazeres, desde observar e interagir com as falas e expressões corporais, até compreender as ações de alguns núcleos familiares. Essas condutas foram manifestadas como práticas sociais, por representarem um conjunto de ações humanas na coletividade em busca de manter ou transformar uma dada realidade, organizada na comunhão de pessoas que se reúnem para aprender, refletir, dialogar, construir e conviver com e sobre diversas situações cotidianas.

Nessa categoria elucidamos alguns momentos especificos das visitações, em especial os que apresentavam cenários de alta vulnerabilidade social. A título de exemplo, contamos a história de Davi, um senhor que sofria os impasses burocráticos na tentativa de aposentadoria, ocasionada pela falta de aptidão ao trabalho por conter quatro hérnias de disco e artroses em seus joelhos.

Desamparado pelos direitos civis, o ex-pedreiro, morador nos quartos do fundo de uma casa emprestada por um amigo, era acompanhado pela entidade em ações mais pontuais, como por exemplo, auxílio transporte, alimentação, financiamento de medicamentos, etc. Pretendia-se ainda que ele tivesse avanços em suas ações jurídicas junto ao Instituto Nacional do Seguro Social (INSS) para aposentadoria, bem como possibilitar a devolução de seus movimentos corporais, uma vez que Davi se encontrava impossibilitado de caminhar sem dores. 
A realidade vivida por Davis apresentou significativa por despertar sentimentos de inconformidade, através da injustiça social apresentada ao se olhar um trabalhador sem receber seus direitos, tendo em seu estado físico pioras que ao longo do tempo se manifestavam mais severamente. Tais aspectos legitimaram um impar momento de aprendizado e oportunidade para o educar-se no convivio com o outro. Ao ser perguntado por um membro da entidade sobre as ações indicadas para evitar as dores no joelho, observamos:

[...] 'Davi, mas você está passando o que a gente combinou? Está utilizando o emplastro de batatas? Porque isso tem comprovação científica Davi, a da minha mãe (risadas). Fora que a gente já te deu, além dos medicamentos, tudo o que você precisava para combater de imediato as dores'. Davi sinalizou gestualmente com a cabeça que sim e complementou sua resposta dizendo 'Estou passando todo dia batata amassada e comendo farinha do caroço de abacate' (sic) (DIÁRIO DE CAMPO I).

Nesse momento refletimos acerca dos conhecimentos apresentados nas falas da coordenadora e Davi, os quais para além dos consideráveis e não menos importantes saberes da cultura popular (CATENACCI, 2007) ajudam a comprovar alguns apontamentos inéditos para os pesquisadores. O emplastro de batatas potencialmente funciona como um possivel analgésico no combate da dor na região lombar, necessitando apenas cozinhar as batatas, amassá-las e aplicar sobre a área afetada (INNATIA, 2017).

Por sua vez, o caroço de abacate possui propriedades antiinflamatórias e antioxidantes, devendo ser ralado, secado e triturado em liquidificador para poder converter-se em uma espécie de farinha, para consumo em refeições (QUIMICA 
LIMENTAR, 2017). Esses dois exemplos ilustram alguns conhecimentos populares - processos educativos, construídos nos diálogos na primeira visita junto ao grupo.

Sobre o quadro das debilidades físicas apresentadas, o pesquisador inserido a campo disse a Davi que em um quadro de artrose é interessante que, após uma devida avaliação por parte de fisioterapeutas, médicos ou especialistas da área, ele inicie um programa de exercícios físicos devidamente orientado por um profissional de educação física, para que assim reabilite suas capacidades e funções de movimento (DIÁRIO DE CAMPO I).

No dado contexto, foram observados os cuidados exigidos durante o diálogo. Ou seja, dialogar requer cuidados já que as préconcepções podem afetar as ações, por mais bem intencionadas que sejam. Ainda que o desejo fosse a melhoria da saúde de Davi, foi importante um olhar sensivel que entendesse e transpassasse a ideia de assistencialismo puro e material que entidades por vezes sugerem. Para isso, ainda tomamos por referência a seguinte fração de um dos diários:

[...] pensar em como Davi poderia ser abordado e sensibilizado para suas próprias necessidades, em que acreditávamos, poderia somar na tentativa de melhores encaminhamentos para soluções de seus problemas e deflagrou também que estávamos impondo nossas ideias e nossas verdades. $O$ fato de considerar apenas o 'saber de experiência feito' de quem se propõe a intervir, e não o do sujeito em assistência, dá mostras de que a concepção de uma resolução mais efetiva por vezes não considera a história do sujeito, o que em grande medida é problemática, pois desconsidera todo um contexto de vida e torna arbitrária a intenção, a ação do que poderia ser melhor para a vida do outro. (DIÁRIO DE CAMPO V)

No contínuo, Davi explicitou que gostaria de dar início a uma prática regular de atividades fisicas orientadas, pedindo ao grupo de voluntários em visitação que repetissem os ditos sobre a 
importância das ações pensadas em prol da saúde para seu filho mais velho, que se encontrava no local. Segundo Davi, seu filho saberia melhor explicar "as coisas" para ele do que qualquer outra pessoa. Assim:

[...] aos poucos se pode perceber a necessidade daquele senhor em expressar suas opiniões, bem como o dever dos voluntários em missão de olhar para ele para muito além de seus problemas emergentes (DIÁRIO DE CAMPO IX).

A humildade no reconhecimento de não querer nos ofender, bem como necessitar de um terceiro para que as informações fizessem mais sentido, foi mais uma aprendizagem fornecida por ele. Esse fragmento da visita em si foi semeador de reflexões sobre um mundo em que cada vez mais o outro é negado e a autossuficiência rege o modo egoísta com que lidamos com nossas vidas e a vida do semelhante. Tal ação desse senhor lançou luzes para o reconhecimento, humildade e honestidade de quem vê no próximo um meio para ser mais (FREIRE, 1992), galgando assim as pretendidas melhorias no contínuo de sua vida.

Outro núcleo familiar visitado foi o de Josi, jovem mãe de quatro filhos com idade entre 3 e 7 anos, recentemente viúva, desempregada. Tal jovem teve seu sonho de ingressar em uma universidade abruptamente interrompida pelas causalidades da vida em conjunto às obrigações maternais. Sendo complicador do todo, essa mãe no presente cenário precisaria trabalhar para subsidiar o sustento de seus filhos, mas tal ação foi impossibilitada por não ter parentes na cidade para se responsabilizar pelas crianças.

Com 17 anos de idade, Josi mudou-se para a cidade lócus deste estudo, na companhia de seu marido, o qual atuou como 
ajudante de fretes pela cidade por mais de 5 anos. Com o advento do falecimento do esposo por acidente de trânsito e sem condições financeiras para retornar a sua cidade natal, a jovem se dedica integralmente ao cumprimento da trajetória escolar e de cuidados da saúde de seus filhos. Essa família é assistida e tem suas contas financiadas pela entidade filantrópica em questão.

Tamanhas problemáticas e sequência de eventos em sua vida, justificariam e configurariam um quadro desolador no contexto afetivo, material e psicológico. Porém, o que se notou durante as seguidas visitações naquele núcleo foi a serenidade e a esperança de uma mulher que enxerga em seus filhos a motivação mais que suficiente para seguir em frente e que não dispensa sonhar com dias/condições melhores. Diante ao cenário, foi impulsiva a sensibilização com tal quadro de vida, “[...] o olhar para brinquedos de crianças por todo chão da casa, o que em verdade emociona ao se pensar a simplicidade e limitações que os filhos da jovem ali confrontavam diariamente" (DIÁRIO DE CAMPO II).

A superação e a não reclamação mediante tantos desafios apresentados na vida de Josi assemelha-se à realidade de milhares de mulheres brasileiras que criam seus filhos sem a presença paterna. No caso esmiuçado, Josi ainda assim se dispõe a trabalhar em meios informais, em horários que combinem a presença de dois dos quatro filhos nas escolas e creche e não se acomoda ao querer saber como evoluir no trabalho e no âmbito dos estudos, vide suas perguntas sobre como ingressar em Universidades hoje, que nos inspiram como exemplo. O modo como essa jovem mãe encarou a sua vida foi manifesto claro de 
fraternidade e esperança, como aqui é recordado a partir do Diário de campo II

[...] ainda que com faltas significativas no campo afetivo e material por conta da distância de seus parentes, falecimento do marido e a simplicidade do lar, segue sua vida como modelo raro de dignidade em meio a tantos desafios.

Em outro núcleo familiar, tivemos a oportunidade de conhecer Joana, uma senhora de 62 anos, mãe de onze filhos homens e que vivia atualmente com subsídios provindos do governo por se encontrar inapta ao trabalho devido uma doença crônica, trombose, que lhe acabara de custar a amputação de uma de suas pernas. Com Dona Joana as experiências se diferenciaram, pois ao escutar sua história de vida aprendemos saberes e fazeres de vida que nenhum outro âmbito social havia nos ensinado. Diante disso, nos questionávamos: como é possivel criar onze filhos frente às dificuldades financeiras, somada às dificuldades de saúde por ocorrência de uma doença que a limitava fisicamente?

$\mathrm{Na}$ contra mão das subjetividades pré-estabelecidas pelo grupo de visitação, Dona Joana não protestava sobre sua vida ou sobre a falta de esperança de um dia ainda emergir as conjunturas financeiramente mais satisfatória, mas o que era recorrente em sua oratória era a indignação pelo fato de não poder trabalhar. Um dos integrantes do grupo, na tentativa de minimizar algumas poucas dores acusadas por Dona Joana na região da amputação compartilhou alguns saberes adquiridos mediante a formação em educação física. Contava à Joana sobre os beneficios que uma série de alongamentos poderia trazer se a mesma se propusesse a realizá-los diariamente, na frequência de três vezes 
ao dia. Joana, ao escutar a proposta, sinalizou positivamente em demonstração de aceite e, assim, o integrante demonstrou os gestuais corporais para que aquela senhora pudesse memorizar e realizar tais movimentos nos dias em que estivesse sozinha.

Enquanto ali compreendiamos que Joana tinha valorizado os 'saberes de experiência feito' de um integrante do grupo, por estar interessada e com propósitos de incorporar tais práticas no seu dia a dia, havia outro lado destacado e percebido em nossas trocas. Joana insistia na saudade sentida de trabalhar. Em um de seus relatos, pôde-se sentir a importância do trabalho, mais precisamente do ato de trabalhar, na história de vida dessa mulher:

[...] perguntada sobre seu último trabalho e com o que trabalhava, Dona Joana disse que sustentou, criou, fez sua história e de mais onze filhos, só 'panhando café', e que o gosto de um café 'panhado na saia' não tinha igual. Encerrou falando que nunca fez outra coisa na vida e sentia muita saudade de apanhar café na saia (sic) (DIÁRIO DE CAMPO III).

Agregava-se nesse momento mais um conhecimento permitido pelos saberes de experiências e feitos de Dona Joana. Ao narrar o fato de trabalhar e sustentar todos seus filhos, a senhora ensinava no mínimo dois novos saberes pelos seus fazeres. Primeiro o termo "saia", que faz alusão à parte mais próxima ao solo de uma plantação de café e, o segundo, sobre a variação de sabores que o café apresenta em sua forma líquida de acordo com o modo em que é colhido. Potencialmente, tais informes encontram sustento na cultura popular, fato que legitima ainda mais o processo humanizado enquanto legado informativo das gerações. 
Sobre o saber de experiência, temos que esse é o adquirido no modo como os sujeitos respondem aos acontecimentos da vida e os sentidos que se esses atribuem aos ocorridos. Relembrando Larossa-Bondía (2002, p. 27):

Se a experiência é o que nos acontece e se o saber da
experiência tem a ver com a elaboração do sentido ou do
sem-sentido do que nos acontece, trata-se de um saber
finito, ligado à existência de um individuo ou de uma
comunidade humana particular; ou, de um modo ainda
mais explícito, trata-se de um saber que revela ao homem
concreto e singular, entendido individual ou
coletivamente, o sentido ou o sem-sentido de sua própria
existência, de sua própria finitude. Por isso, o saber da
experiência é um saber particular, subjetivo, relativo,
contingente, pessoal.

Com isso, entendemos as experiências como uma ferramenta de mediação entre os sujeitos e as visitações, por suas vezes, possibilitaram situações inéditas de aprendizagens significativas. Suspendendo pré-concepções e julgamentos, o ato de conhecer e conviver com os indivíduos assistidos pela entidade filantrópica permitiu momentos enigmáticos e grandiosos na perspectiva do educar-se em comunhão, por meio das trocas dos 'saberes de experiência feito'.

Ao analisar a mudança da forma de lançar olhares e o cuidado ao observar pelo viés humanizador as circunstâncias dos sujeitos em pesquisa, a própria mudança de quem pesquisa e suas aprendizagens oriundas dos distintos episódios e ocasiões compuseram a materialização de ensinamentos que o contexto de visitações forneceu. 


\subsection{Educar-se com o diálogo: a prática amorosa na alteridade}

Educar-se, no sentido mais amplo da expressão, solidifica-se na necessidade primeira do diálogo e da alteridade, potencialmente ilustrados pelo saber freireano acerca do conceito: ninguém se educa sozinho, tampouco ninguém somente educa ou só é educado. A ideia de diálogo deve ser entendida como o

[...] encontro entre os homens, mediatizados pelo mundo, para designá-lo. Se ao dizer suas palavras, ao chamar ao mundo, os homens o transformam, o diálogo impõe-se como o caminho pelo qual os homens encontram seu significado enquanto homens; o diálogo é, pois, uma necessidade existencial (FREIRE, 1980, p. 82-83).

Ao pensar a necessidade existencial dos seres, bem como a abertura para o novo em qualquer perspectiva de iniciação dos diálogos, temos que dialogar, sobretudo, exige verdade e criticidade, na mesma medida que requer sensibilidade, pois é na ação concreta de diálogo que o processo educacional opera e se dá como criador, transformador, potencializador e libertador (FREIRE, 1987).

Ao rememorarmos a visitação à casa de Davi, ganha relevo no recorte descrito pelo pesquisador a campo o seguinte trecho de diário:

Tudo o que ocorreu, em certa medida, foi surpresa. Ao mesmo tempo em que não nos permitíamos planejar ideias de auxilio pelo diálogo (em verdade também não poderíamos, pois enquanto grupo não eram todos que conheciam o sujeito), também não nos contaminamos no sentido de antecipar as necessidades daqueles que iriam relatar suas vidas e seus problemas no cotidiano, o que é ponto interessante, pois assim policiamos os préjulgamentos e tendemos à prática amorosa, tão necessária para qualquer ação solidária (DIÁRIO DE CAMPO VIII). 
Em tal fragmento, o diálogo também é indicado como prática amorosa. Essa prática deve ser simplesmente entendida como ato de amor ao outro e pelo outro e, ao mesmo tempo, tão fundamental para o diálogo comprometido com o mundo e a humanidade (FREIRE, 1980). Amorosidade essa manifesta na comovente fala de Josi, em que, na última das visitações registradas decorrentes das inserções, agradecia o intermédio da coordenadora da entidade filantrópica por indicar e encaminhar o mais novo posto de trabalho remunerado da jovem.

Assumindo a função de diarista de uma casa, Josi, grata pela ideia de que seu novo emprego poderia prover sustento e mais dignidade para seus filhos, expressou seus sentimentos conforme demonstra o registro:

Dizia ela (Josi) que havia ido à missa no dia anterior agradecer a Deus pela oportunidade e que sabia que aquela era uma chance que demandaria muito de seu esforço, porém que poderia ser uma forma de melhorar a vida, sua própria e a de seus filhos. Segundo suas palavras, 'sei que vou ficar meio louca né, porque não vai ser fácil cuidar da minha casa, dos meninos e trabalhar de segunda a sábado, mas eu estou feliz, você não imagina o quanto. As coisas estão dificeis né, mas tem muito exemplo bom pra gente se apegar. Eu quando converso com você, quando eu converso olhando nos olhos, eu sinto as coisas sabe. Eu vejo que você quer me ajudar, então eu preciso me ajudar. Eu, assim, não posso te comprar nenhum presente, mas se pudesse já estaria comprado. O que tá sendo feito por mim eu nunca vou esquecer e vou fazer igual pra quem eu puder, um dia se eu puder' (sic) (DIÁRIO DE CAMPO VI).

No excerto nota-se amor e prática desse sentimento, manifestados pela e na alteridade, materializados nas palavras proferidas em diálogo quando a coordenadora da entidade responde os ditos da jovem mãe que acabara de agradecer o que lhe sugere ser a mudança de sua vida no presente momento. Essa 
percepção apenas foi possivel pelos laços de confiança e convivência firmados, dos quais decorrem saberes, conceitos e ideias construídas e compartilhadas em comunhão. Nesse movimento ocorrem processos educativos e a produção de cultura como "[...] permanente recriação do mundo, da existência [...]" (FIORI, 1991, p. 89).

Não sendo possivel mensurar, porém tampouco negar, o momento de resposta da coordenadora para a jovem mãe explicitou a satisfação, serenidade e amorosidade, de modo que o exercício de alteridade pode ser visto quando o diálogo humaniza e aproxima as pessoas. Destacado em diário de campo, aponta-se que:

[...] foi possivel perceber naquele momento que as palavras ditas anteriormente por Josi foram proferidas de modo aberto, na gratuidade, com ânimos de quem sabia que a esperança havia ganhado corpo. Em um ambiente tomado pelo sentimentalismo de quem optou por crer em valores como a integridade, justiça e resiliência, encontrava-se de um lado a responsável pela entidade e de outro uma pessoa auxiliada pela entidade, mas que podiam ser confundidas, dado o estado de graça que a notícia de um novo emprego havia gerado naquele local, mais precisamente naquele exato momento descrito.Em sua fala a coordenadora dizia: 'Você, Josi, ensina muito a muita gente. Ensina a não desistir, perseverar e brigar sabe? Eu vim da Bahia e de lá meus avós sempre diziam que só está morto quem não peleia e você peleia bonito. Gente como você, garota, tem que estar por aí, porque é testemunho vivo de que se vale a pena viver, se dedicar pelo próximo, pelo que se acredita e pelo que se ama. $\mathrm{Me}$ ponho em seu lugar e só assim eu consigo ficar mais feliz do que como você deve estar agora' (sic) (DIÁRIO DE CAMPO VI).

Em concordância com Freire (1980), o diálogo, enquanto instrumento para libertação, deve ser desenvolvido com o amor em sua essência. Nessa direção, o amor é ao mesmo tempo o fundamento do diálogo e o próprio diálogo (FREIRE, 1980, p. 83). 
Esse conceito permite e induz concomitantemente à ação dialógica, pois se nele não está implicado o amor, o diálogo não é diálogo, ou seja, não há diálogo, mas sim extensão de palavras.

Segundo esse conceito, a própria ação de educar não é possivel sem o diálogo, pois ele é a palavra dita e ouvida com coragem, é o dito em sua transcendente forma, assumida como instrumento que torna possivel a libertação e galga a transformação social. Desse modo, a existência humana deve se nutrir de palavras verdadeiras/diálogos verdadeiros (FREIRE, 1987), comprometidas com a perspectiva do Ser Mais dos sujeitos.

A expressão Ser Mais diz respeito ao processo constante do sujeito por sua humanização. Notadamente, implica uma postura de sujeitos conscientes que querem, refletem e agem para transporem situações que os deixam limitados, por vezes, situações que os impossibilitam de concretizarem suas vontades; “[...] trata-se das barreiras 'situações-limites' que impedem alguns e algumas de sonhar o sonho" (FREIRE, 1992, p. 207). A perspectiva do Ser Mais para e entre esses sujeitos implica a realização de suas próprias ações com autoria, ofertando a possibilidade de concretizar suas vontades e expectativas, tornando-as significativamente compreensiveis e úteis em termos de realidade.

Para Fiori (1991), a educação é um esforço humano de construir-se e de reconstruir-se, é uma busca pela plenitude da vida humana, pelo Ser Mais, é um movimento em direção à liberdade. Segundo o autor, o humano é um ser capaz de criar e recriar e de recriar-se, sendo a educação um processo de reinvenção do mundo. 
A concepção de dialogar tem como premissa o encontro de sujeitos para a pronúncia do mundo e sua posterior transformação calcada no Ser Mais. A transformação dita e desejada pela ideia de uma sociedade mais justa e humanizada requer ações que possam ser observadas, acompanhadas, convividas e dialogadas ao longo das inserções no contexto das visitações. Tocando na esperança para e pela humanização, podese identificar nos diálogos entre visitados/visitadas e integrantes da entidade filantrópica a ação educadora em que os sujeitos aprendem na e com a diferença, a partir da leitura de mundo do outro e com o outro.

\section{CONSIDERAÇÕES FINAIS}

Com o propósito decompreender os processos educativos consolidados em missões populares em saúde e refletir acerca da humanização e da alteridade no trato das relações humanas, consideramos que as práticas e processos educativos construídos a partir dos "saberes de experiência" e as relações humanas tecidas na relação dialógica de alteridade e amorosidade contribuíram positivamente para a nossa formação pessoal e profissional. Do mesmo modo, arriscamos dizer que tais contribuições foram percebidas pelos participantes da pesquisa.

Percebemos que a entidade filantrópica, enquanto missão popular, se caracterizou como uma prática social incumbida pela caridade e compromisso político, religioso, ético e, sobretudo, educativo. As experiências advindas do conjunto de inserções nos possibilitaram "fazer" e "pensar" a educação como manifestação de saberes e experiências cotidianamente construídas e compartilhadas entre aqueles que apresentam a intenção de 
ajudar e os que são ajudados. Ou seja, os sujeitos participantes e os sujeitos pesquisadores aprendem e ensinam, ajudam e são ajudados, ao passo que compartilham os seus mundos e os transformam num ato de comunhão.

Com isso, consideramos que as relações humanas proporcionadas pelas visitações possibilitaram 0 compartilhamento e compreensões acerca de mundos distintos, tendo no respeito, na alteridade e na amorosidade a condição primordial para a valorização das visões de mundo e cultura dos envolvidos no processo.

Destacamos que as relações estabelecidas ao decorrer das visitações não se findaram com o término do estudo, tampouco representam o término de vínculo do relator para com a entidade filantrópica e seus assistidos, ao contrário, firmamos aqui a responsabilidade social adquirida nesse período e o compromisso de participação, com vistas em ajudar e em ser ajudado, no que tange à adoção de práticas humanas pautadas na alteridade e amorosidade.

Em termos de ensinamento à vida, estamos convencidos de que os resultados obtidos foram mais significativos do que as próprias leituras e estudos promovidos em berços acadêmicos, precursora deste estudo. Contudo, a partir das teorias discutidas no seio da universidade, consideramos o processo de pesquisa e formação humana de modo dialético e complementar entre si, isto é, os processos educativos advindos da experiência relatada somente foram percebidos enquanto práticas humanizadoras, devido ao período de reflexões à luz das teorias. 


\section{REFERÊNCIAS}

BARDIN, L. Análise de conteúdo.Lisboa: Edições 70, 1979.

BOGDAN, R.; BIKLEN, S. Notas de campo. In: .Investigação qualitativa em educação: uma introdução à teoria e aos métodos. Porto: Porto Editora, 1994, p. 150-175.

BRANDÃO, C. R. Qualidade de vida, vida de qualidade e qualidade da vida. In:__ A canção das sete cores: educando para a paz.

São Paulo: Contexto, 2005, p. 27-72.

CATENACCI, V. Cultura popular entre a tradição e a transformação. São Paulo emPerspectiva, São Paulo, v.15, n.2, Apr./June, 2001.Disponivel em:

<www.scielo.br/pdf/spp/v15n2/8574.pdf>. Acesso em: 10 out. 2007.

COTA, M. C. De professores e carpinteiros: encontros e desencontros entreteoria e prática na construção da prática profissional. Educação e Filosofia, v. 14, n. 27/28, 2000, p. 203222.

FIORI, E. M. Conscientização e educação. In - Educação e Realidade. Porto Alegre: UFRGS, 1986, p. 65-82. .Educação libertadora. In: - Textos escolhidos, v. II, Educação e Política. Porto Alegre: L\&PM, 1991. p. 83-95.

FREIRE, P. Pedagogia do oprimido. 17. ed. Rio de Janeiro: Paz e Terra, 1987.

FREIRE, P. Educação como prática da liberdade. 10. ed. Rio de Janeiro: Paz e Terra, 1980. 1982. . Educação e Mudança. 13. ed. Rio de Janeiro: Paz e Terra, - Pedagogia da esperança: um reencontro com a pedagogia do oprimido. 13. ed. Rio de Janeiro: Paz e Terra, 1992. INNATIA. 4 remédios simples para dor lombar. Disponivel em: <http://br.innatia.com/c-saude-musculo-esqueletico/a-4remedios-simples-para-dor-lombar-4011.html>. Acesso em: 05 maio 2017.

LARROSA-BONDÍA, J. Notas sobre a experiência e o saber de experiência. Revista Brasileira de Educação, n. 19, p. 20-28, jan./abr. 2002.

MINAYO, M. C. S. (Org.). Pesquisa social: teoria, método e criatividade. Petrópolis: Vozes, 2001.

QUIMICALIMENTAR. Caroço de abacate possui ação antifúngica e é antibiótico natural. Disponível em:

<http:/ / www.quimicalimentar.com.br/caroco-de-abacate-possui- 
acao-antifungica-e-e-antibiotico-natural/>. Acesso em: 25 maio 2017.

SILVA, P. B. G. Aprender a conduzir a própria vida: dimensões do educar-se entre afrodescendentes e africanos. In: BARBORA, L. M. de A.; SILVA, P. G. e S., SILVÉRIO, V. R. De preto a afrodescendente: trajetos de pesquisa sobre relações ético-raciais no Brasil. São Carlos: EDUFSCar, 2004. p. 181-197. SSVP SOCIEDADE SÃO VICENTE DE PAULO. A sociedade de São Vicente de Paulo. Disponível em: <http://www.ssvpbrasil.org.br/?pg=sobre_a_ssvp>. Acesso em: 25 maio 2017.

OLIVEIRA, M. W. de; SILVA, P. B. G. e; GONÇALVES JUNIOR, L.; MONTRONE, A. V. G.; JOLY, I. Z. L. Processos educativos em práticas sociais: reflexões teóricas e metodológicas sobre pesquisa educacional em espaços sociais. Anais...Caxambu: ANPEd, v.1. p. 1-17, 2009.

OLIVEIRA, M. W. de; STOTZ, E. N. Perspectivas de diálogo entre organizações não governamentais e instituição acadêmica: o convívio metodológico. Anais da $27^{a}$ Reunião da ANPED, 200. 1CD ROM. 